\title{
The Obstacles Women Face in Gaining Access to Special Operations Forces
}

\author{
João Reis, Rafael Gonçalves, Sofia Menezes and Manuela Kaczynska
}

\begin{abstract}
The aim of this article is to provide exploratory insights regarding women integration in the special operations forces. The methodological approach is qualitative and employs a case study research in the Portuguese Army. It includes multiple sources of data collection for corroboration purposes, namely semi-structured interviews, direct observation and official documents. Although it has been considered a hot-topic in the Portuguese armed forces, and as the Portuguese Republic establishes the legal means to integrate women in all professional areas, reality shows that up to the present days no women have been part of the special operations forces. In light with the above, we evidence some obstacles that women are facing in gaining access to the Portuguese special operations forces, and we present Portugal in comparative perspective with two successful case studies.
\end{abstract}

Keywords Women - Special operations forces $\cdot$ Portuguese Army $\cdot$ Military $\cdot$ Gender $\cdot$ Integration $\cdot$ Case study

\footnotetext{
J. Reis ( $\square)$

Department of Military Science, Military Academy, GOVCOPP, Lisbon, Portugal

e-mail: joao.reis@ academiamilitar.pt

R. Gonçalves

Department of Military Science, Military Academy, Lisbon, Portugal

e-mail: goncalves.inf@gmail.com

\section{S. Menezes}

Department of Management and Leadership, CINAMIL, Lisbon, Portugal

e-mail: sofia.menezes@academiamilitar.pt

M. Kaczynska

Tadeusz Kościuszko Land Forces Military University, Polish Land Forces Military University, Wrocław, Poland

e-mail: manuelakaczynska@gmail.com
} 


\section{Introduction}

Special operations forces have become increasingly central to the wars of the twentyfirst century [1]. Every country has military units composed of personnel specially trained and equipped, with higher level of readiness than general military units and typically regarded as elite- these forces are collectively known as special operations forces [2].

Despite consistent downsizing, over the past two decades the armed forces of the industrial democracies have seen extensive growth in special operations forces (SOF). By means of increasing numbers of personnel and of more frequent deployments, SOF units have wielded considerable influence in conflicts around the world [3]. The remarkable growth of SOF is part of the military organizations and has had to dramatically adapt to their diversity and changing external and internal environments [4]. As Shamir and Ben-Ari [4] argue, SOF are unique in that they are specialized generalists, local-level integrators that link between the tactical operational and strategical levels of actions, therefore being hybrid forms of organizational response to environmental pressures.

In Portugal, women are not precluded from serving in any military unit by law; however, the reality is that up to the present days no women have been part of the Portuguese SOF. The reasons are yet to be determined, since all the statistics prove the commitment of women to combat- "in approximately 10 years of combat operations in Iraq and Afghanistan, over 283 thousand female members have been deployed, over 800 have been wounded and over 130 have died" [5, p. 1]. Burrelli [5] reinforces that, on numerous occasions, women have been recognized for their heroism, two of which earning US Silver Star medals.

We have conducted a research of the literature and we have detected the existence of similar articles. What is the novelty brought by our article? Most gender studies on special operations forces are from the United States (US) Army, mainly after the congress mandated that US SOF adopted gender-neutral occupational performance standards by 2016. After that year, females were no longer barred from applying to SOF rigorous pipeline, and as shown in operations in Afghanistan and Iraq, female enablers made significant, unique contributions to ground combat and SOF missions [6]. Gasca et al. [6] even went further, by arguing that many of these unique contributions, such as the ability to interact with indigenous children and female adults (forbidden by local customs or religious beliefs from interacting with male service members), were critical to mission success. Moreover, women have been employed successively in SOF units worldwide, though some Western countries still subsist to that trend. It is to that extent that our article provides differentiating contribution, as it analyses the reasons that led a Western European Army to not embrace women in their ranks.

This article is organized as follows: in the next sections, we review the literature and discuss the gender concept on the military forces. Then, we describe the methodological approach, the study sample and the data analysis. 
The following sections discuss the empirical results, by providing statements from the respondents. Finally, we present the academic and practical insights, limitations and guidelines for future research.

\section{Literature Review}

The issue of women in the military has always been, and is likely to remain, one of the most controversial issues in the study of military institutions [7]. Therefore, the issue of women's empowerment and gender equality is at the top of agendas across the world, as gender inequality is widespread in all cultures [8]. By the beginning of the twenty-first century, most Western democratic countries had admitted and increased the number of women in their armed forces; although restrictions persisted, many were lifted: women were progressively allowed to enter military academies and given access to a wide variety of positions and functions [9]. As the global momentum towards the acceptance of women in ground close combat (GCC) continues to increase, the USA decided, in December 2015, to open all GCC role to women without exception-a controversial and, some say, politically motivated decision [10]. The number of women service in the military and deployed to active duty is unprecedented in the history of developed economies-in the US Armed Services, women constitutes approximately $14.5 \%$ of the 1.4 million active component and $18 \%$ of the 850,000 reserve component [11]. Yet, little attention has been paid to women integration on military life. Thus, the history of women's military participation shows that they have systematically been excluded from warfare as warriors or have participated only in exceptional circumstances [7].

In the USA, between 2003 and 2013, women were technically banned from direct assignment to ground combat units; however, the US military deployed all-female counterinsurgent teams in Iraq and Afghanistan [10, 12]. Greenburg [12] also argues that in various forms, these teams searched Iraqi women at checkpoints and in home raids, provided medical assistance to Afghan women and children. Adding to this, women participated in highly combative special operations missions alongside Army Rangers and Green Berets in Afghanistan. Although this empirical evidence has been demonstrated, women are still being marginalized in several military institutions around the world.

The gender theme has raised attention all over the world, and it is not just about the USA. In 2016, the Canadian Armed Forces (CAF) launched a recruitment campaign aimed specifically at women, in which the military's - and society's-ambivalence towards female participation was palpable-one of the goals of the campaign was to recruit sufficient women so as to change the CAF's violent, sexist and sexualized culture [13]. The stereotype has made women's integration in the armed forces challenging and supports a gender binary "that characterizes men as active, women as passive" and is damaging their credibility as combat soldiers [13]. The reality is that many nations still do not allow women to serve in combat roles or in submarines [14]. Still, a greater number of combat-support and possibly service-support roles 
performed by women will increasingly mean they will find themselves in combat zones [10].

Szayna et al. [15] have recently conducted a survey about women integration in SOF and concluded an opposition to opening SOF specialties to women in both deep and wide, with high levels of opposition across all SOF elements. Those authors' analysis of responses to open-ended questions suggests that this opposition also is deep-seated and intensely felt. Szayna et al. [15] concluded that principal sources of this opposition are the belief among SOF personnel that women do not have the physical capabilities and other to meet the demands of the specialties; however, the lower level of opposition to women in SOF units than specialties, as well as the fact that about four in ten of our respondents agreed that women might be helpful in conducting sensitive operations and communicating with local populations might present additional opportunities for the participation of women in SOF. Sunde and Kristiansen [16] argue in the same direction, stating that women in certain urban special reconnaissance (SR) roles will increase the SR capacity in small states NATO SOF. As the authors studied the Norwegian Special Operations Forces (NORSOF) case, the found that conducting SR in urban areas often involves indirect or direct human contact. Female SR operators will tear up the stereotypical signature of male operators, and thereby provide operational flexibility and will enable a SOF unit to handle a broader range of SR missions, consequently increasing the strategic and political value of that unit [16]. Meanwhile, Knarr et al. [17] conducted a survey with Retired SOF Senior Leaders who agreed that any chance of success requires no compromise in the assessment and selection standards across the SOF enterprise (e.g. "Do not lower the standards for physical and mental endurance", "Keep the standard!"), this followed a focus group concerned with the ability of mixed-gender teams to effectively perform direct action missions, perceived to require the highest level of physical capabilities. From a NATO SOF integration, Kristiansen [18] suggests to analyse the different roles and to produce a selection and education programme that suits the standards for these specific roles, instead of forcing women through the SOF selection and education programmes that already exists. In Kristiansen's [18] view, the physical standards for women NATO SOF need to be adapted, based on potential relevant roles for female operators, such as the level of risk in NATO SOF is expected to be handled in order to accomplish high-risk missions.

\section{Methodology}

This research is qualitative and exploratory, trying to explain a phenomenon for which little or no empirical data exist [19]. To that end, we have conducted a case study to enable the research to acquire in-depth and holistic understanding of multiple aspects of the phenomenon, as well as the interrelationships between different aspects [20].

We have built this study on multiple sources of data collection, for triangulation and corroboration purposes. Those sources of data collection consist on semistructured interviews, direct observations and institutional documents. A case study 
that relies on multiple sources prevents the exclusive reliance on a single data collection method, thus aiding to neutralize any bias inherent to a particular data source [21].

The participants for the interviews were selected according to the following characteristics: six servicemen with the army special operations course and six servicewomen from the Portuguese Army. The researchers made use of their personal network in the army to identify the best respondents. The selected respondents were chosen according to their different functional areas and different levels of responsibility in the military organization. Thus, the study was carried out from operational to administrative areas, and the respondents' ranks ranged from master sergeant to colonel. The direct observations involved systematically seeing and listening [22] and mainly consisted in informal interviews and notes that were collected into a research diary. Those notes contained the respondents' reactions and expressions to certain type of questions, while the informal interviews had mainly served to deepen the knowledge that otherwise would not possible to ascertain during the formal interviews. The analysis of institution documents served essentially to understand the Portuguese concept of special operations forces, their main missions and to understand into what extent the training/course can be an obstacle to women integration.

Similar to other studies, before proceeding, we took the following details in consideration: first, the women in SOF survey dealt with a highly politicized issue in Portugal as respondents might have viewed the survey as an influence to policy, rather than an opportunity to identify the potential challenges and opportunities for smoothing implementation and to change mentalities [15]. Therefore, we believe some respondents might not have answered in an overt way-to mitigate a possible disruption, we have cross-checked these answers with secondary sources of data collection. In order to enhance the reliability and validity of the case study research, we have followed a research protocol (Appendix) and the transcriptions were doublechecked by the participants to avoid misinterpretations.

After we collected the data, all the text was analysed according to the technique of content analysis [23]. We had preliminary categorized textual data into categories, to identify consistent patterns and relationships between variables in a way of reducing data and making sense of them [21]. The study was resorted to the use of qualitative data analysis software known as NVivo, which allowed to code in order to build and hierarchize categories and subcategories to identify the main stream and/or new ideas.

\section{Findings}

This section presents the results of the case study research. In addition, we also provide an insightful contribution, by comparing two European realities, Portuguese and Polish, from military point of view of the authors. Finally, we present an inspiring case, witnessed from a military mission in Afghanistan. 


\subsection{The Case Study of the Portuguese Special Operations Forces}

The special operations forces have a complex organization, a diverse set of capabilities and a broad range of officially assigned missions, all of which can make it difficult to understand exactly who special operation forces are and how they should be used [24]. In Portugal, the army special operation forces are especially assigned to conduct operations of special reconnaissance, direct actions and military assistance. Moreover, the directive $\mathrm{n}^{\circ} 90$ from the Chief of Staff of the Portuguese Army (CSPA) states that, due to SOF unique characteristics, they act within the spectrum of crisis response operations, combat operations for search and rescue and counterterrorism operations [25, pp. 2-4].

The respondents have supported the ideal of combat-support and service-support roles to be performed by women in the special operations forces. At the same time servicewomen argued that women might be helpful in conducting sensitive operations with local population, they have also claimed that if women gather enough physical and psychological robustness, they should be included in SOF combat missions. In addition, informal interviews have revealed that until very recently the physical component of SOF in Portugal was highly valued; this information is also corroborated with internal documents. However, this paradigm has been changing, while the technical and intellectual component is highly appreciated, e.g. in order to perform complex missions that involves modern military technologies [26]. Although some scholars and SOF servicemen make a distinction about different physical capabilities, there are no scientific evidence concerning technical and intellectual discrepancies between men and women. Furthermore, a survey in Portugal shows that currently the number of women attending higher education in Portugal surpasses that of men [27].

One of the possible solutions to integrate women into the Portuguese special operations forces is what servicewomen call "pioneers", that is, a group of women being able to successfully undertake a special operations course and combat operations alongside with men. Demystifying the subject, thrust and inspiration may be the formula that women need to undertake a life in SOF units. The interviewed servicewomen are well informed about the progress made until the present days in both US and Afghan SOF. If women are willing to attend and complete a special operations course, they will encourage and inspire others to move forward as they have proven that this opportunity is within the reach of every person. This opportunity is getting closer, because although official documents show that the special operations course is still very demanding from the physical point of view, it is increasingly becoming more technical, whereas the adaptability, the complex technical and tactical capabilities of SOF students are pushed to limit. Nevertheless, direct observations have pointed out that some servicewomen are reluctant about the robustness level that would be imparted to them during the SOF course, when compared with their male counterparts, in order to make them give up. Apparently, the idea of SOF operators is that integration of women into the special operations forces might be identified 
as a reduction of the parameters of physical robustness, which in their mind could place the Portuguese SOF in a situation of fragility when compared with other special forces (e.g. Commandos).

The Portuguese paratroopers have a different understanding - they are considered a special force, but they also integrate women in their ranks. The Portuguese armed forces included women for the first time in 1961, when Isabela Bandeira de Mello, the first civilian parachutist women in Portugal, influenced the armed forces to create an all-female corps of nurses to be deployed to the colonial war [28]. The first women were then trained as parachutists, with the mission of providing nursing assistance during the war in Portugal's overseas territories in Africa and served in combat areas in Angola, Mozambique and Guinea-Bissau during the 13-year colonial conflict [29]. On numerous occasions, these female paratroopers had been recognized for their heroism: an example is Maria Justino da Silva, who was wounded in combat in Mozambique, during an evacuation mission to rescue wounded soldiers [30]. Since those days, women from the paratrooper forces had been well accepted and integrated in all types of military operations.

We also considered valuable to present two successful cases and thus to present Portugal in comparative perspective. The next cases were selected due to the authors' affinity with those realities, mainly due to their professional experiences.

\subsection{Comparison with European Countries-The Polish Model}

Currently, Poland employs women in close combat roles [31]. Nowadays, women that complete 5 years of university assume military posts [32]. According to Cawkill et al. [32], from 2003 to 2008 the Polish armed forces made outstanding progresses, as they achieved 1153 servicewomen in the army; moreover, females platoon commanders have been deployed to Polish military contingents in Iraq and Afghanistan. Although the Polish Army is given as an example, several European countries integrate women into combat operations-Denmark, Finland, France, Germany, Netherlands, Norway, Romania, Spain and Sweden [31]. Moreover, recent studies argue that female soldiers' experiences refute their male colleagues' assumptions, regarding their ability to serve in combat units [33].

Polish Special Forces comprise five service operation units. The Polish Grupa Reagowania Operacyjino Mobilnego (GROM) is a special operations force unit that has already gained an excellent reputation within the world's special forces communities, while the GROM training is made as realistic as possible as all the training is mainly carried out using live ammunition [34]. Their training is based on three main areas: black tactics that are focused on counterterrorism operations on the ground, green tactics-special operations in enemy's rear and activities associated to the releasing of prisoners of war and blue tactics which involves counterterrorism operations on the sea. Polish Jednostka Wojskowa Komandosów (JWK) is specialized in special 
reconnaissance. Special reconnaissance reinforces national and allied measures and systems to gain information that is relevant to carry out operation in extreme circumstances. The youngest polish special operation force unit is Jednostka Wojskowa AGAT (JW AGAT) that was set up in 2012. This unit involves counterterrorism operation in urban and rural areas. The fourth and last unit is Jednostka Wojskowa NIL (JW NIL); they operate as a support for other special operations force units by providing access to information, commanding and logistic support. According to the constitutional principal of gender equality, both women and men can become professional soldiers; these rules for entering, fulfilling and terminating military service provide equal rights and place the same requirements on both men and women [35]. Currently, this principle is also applied to the special operations forces, as they integrate women at SOF units, especially in logistics areas, but they are not directly involved in tactical operations - this is identified as their main observed obstacle.

\subsection{The Inspiring Struggle-The Afghan Case}

One of the co-authors of this article has served in the NATO Special Operations Component Command-Afghanistan (NSOCC-A). During his duties, as advisor of the Ministry of Interior, he followed the commitment of the North Atlantic Treaty Organization (NATO) gender advisors while accomplishing their duties (train, advise and assist) in order to increase women's representation at all levels of the Afghan National Defence Security Forces (ANDSF). Women operating in the Afghan special security forces (ASSF) may integrate the General Command of Police Special Units under the Ministry of Interior (MoI) or service with the Afghan National Army Special Operations Command under the Ministry of Defence (MoD). Recruiting women to ASSF is clearly a higher challenge when compared with most of the Western countries. Despite this fact, gender discrimination remains an issue within the ANDSF; our belief is that, being pushed by NATO advisors, the Afghan leaders are progressively changing their minds and accepting females' integration into police and army special forces. The sacrifices made by the Afghan women in the line of duty might be seen as an inspiration to developed countries that have not yet been able to successfully integrate women in their SOF.

\section{Concluding Remarks}

In this article, it is concluded that although the physical component of the SOF in Portugal is highly valuable, this paradigm has been changing. Due to some changes, motivated by the use of military technologies, the technical and intellectual component is now appreciated in the Portuguese SOF. Although SOF operators defend a distinction concerning different physical capabilities between men and women, there is no scientific evidence concerning the technical and intellectual discrepancies. It is 
with the aforementioned arguments that we support the integration of women into the Portuguese SOF; in addition, existing examples have shown not only the feasibility of their integration, but also new acting opportunities in all types of military operations.

This article is not free of limitations: due to confidentiality reasons, we have not provided any information about key informants and the respective military unit they serve. It is also limited because of its exploratory nature, but we hope that we can encourage future investigations as it may also be relevant to fill a gap in the literature. However, case studies are difficult to generalize. Thus, the same study in other countries may carry the risk of obtaining contradictory findings. This issue should not be considered a problem itself. To mitigate the generalization aspect, we suggest to adapt our results to each SOF's and country realities.

We instigate academics and practitioners to provide new and insightful contributions to this emergent topic as it represents a fertile opportunity for future research. Future research may focus on the role and impact of women in the Portuguese paratroopers. In addition, we also suggest the role and impact of women in the modern Afghan Armed Forces.

Acknowledgements This project was started under the sponsorship of Erasmus+ programme, which allowed students from different European countries to cooperate. We would like to thank the Portuguese and Polish Army, for their outstanding contribution. Lastly, but not least, we would also like to thank the participation of the anonymous respondents, which greatly contributed to the production of the final results.

\section{Appendix}

Interview protocol—SOF Personnel/Military Women

1. Introduction

- Explain the purpose of the interview

- Explain the reasons for tape recording

- Mention the length of the interview

- Discuss the confidentiality purpose.

2. Generic information

- What is your current professional activity?

- For how long did you work (have you been working) at the Special Operations Forces? (this question is not applied to women)

- For how long have you been working to the Portuguese Army?

- Age? 
3. Generic questions

- What do you think about the integration of women in the Special Operations Forces?

- If you agree to it, in what branches? Why that branch?

- Should women perform tactical/combat operations?

- If not, why?

\subsection{Specific questions}

- Do you know any international model of integration of women in the special operations forces?

- If so, can you give some examples?

- Which model do you consider the most appropriate and why?

- As you know, there are no women in the Portuguese special operations. In your opinion what is the reason?

- What can be done, so that the integration of women in this type of forces would be successful?

- In your opinion, what is the greatest contribution that women can bring to the special operations forces?

4. Closing comments

- Is there anything to add which remained unsaid?

- Are you available to revise the transcription of the interview?

- Thank you for your participation in the interview.

\section{References}

1. Long, A.: NATO special operations: promise and problem. Orbis 58(4), 540-551 (2014)

2. Kirby, S., Harrell, M., Sloan, J.: Why don't minorities join special operations forces? Armed Forces Soc. 26(4), 523-545 (2000)

3. Turnley, J., Michael, K., Ben-Ari, E.: Special Operations Forces in the 21st Century: Perspectives from the Social Sciences. Routledge (2017)

4. Shamir, E., Ben-Ari, E.: The rise of special operations forces: generalized specialization, boundary spanning and military autonomy. J. Strateg. Stud. 41(3), 335-371 (2018)

5. Burrelli, D.: Women in combat: issues for congress. In: Library of Congress Washington DC Congressional Research Service, pp. 1-17 (2013)

6. Gasca, F., Voneida, R., Goedecke, K.: Unique capabilities of women in special operations forces. Spec. Oper. J. 1(2), 105-111 (2015)

7. Carreiras, H.: Gender and The Military: Women in the Armed Forces of Western Democracies. Routledge (2006)

8. Bayeh, E.: The role of empowering women and achieving gender equality to the sustainable development of Ethiopia. Pac. Sci. Rev. B Humanit. Soc. Sci. 2(1), 37-42 (2016)

9. Carreiras, H.: Gender relations in the armed forces: does the draft make a difference? Sicherh. Frieden (S+F)/Secur. Peace, 19-24 (2012)

10. Fitriani, Cooper, R., Matthews, R.: Women in ground close combat. RUSI J. 161(1), 14-24 (2016) 
11. Boyd, M., Bradshaw, W., Robinson, M.: Mental health issues of women deployed to Iraq and Afghanistan. Arch. Psychiatr. Nurs. 27(1), 10-22 (2013)

12. Greenburg, J.: New military femininities: humanitarian violence and the gendered work of war among US servicewomen. Gender Place Cult. 24(8), 1107-1126 (2017)

13. Lane, A.: Special men: the gendered militarization of the Canadian armed forces. Int. J. 72(4), 463-483 (2017)

14. Pinch, F., MacIntyre, A., Browne, P., Okros, A.: Challenge and Change in the Military: Gender and Diversity Issues. Wing Publishing Office (2004)

15. Szayna, T., Larson, E., O’Mahony, A., Robson, S., Schaefer, A., Matthews, M., Polich, M., Ayer, L., Eaton, D., Marcellino, W., Miyashiro, L., Posard, M., Syme, J., Winkelman, Z., Wright, C., Zander-Cotugno, M., Welser, W.: Considerations for Integrating Women into Closed Occupations in US Special Operations Forces. Rand Corporation (2016)

16. Sunde, F., Kristiansen, M.: Defying stereotypes: the untapped potential of integrating female reconnaissance operators into small state NATO SOF. Small Wars J. (2018)

17. Knarr, W., Turnley, J., Stewart, D., Rubright, R., Quirin, J.: Special operations forces mixedgender elite teams (SOFMET): examining socio-cultural dynamics of SOFMET. Joint Special Operations University, Centre for Special Operations Studies and Research, 1-117 (2014)

18. Kristiansen, M.: Women: a NATO special operations forces force multiplier. Small Wars J. (2017)

19. Yin, R.: Case Study Research: Design and Methods. Sage, Thousand Oaks (2003)

20. Gummesson, E.: Qualitative Research in Management. Qualitative Methods in Management Research. Sage, London (1991)

21. Given, L.: The SAGE Encyclopaedia of Qualitative Research Methods, vol. 1-2. Sage, Thousand Oaks (2008)

22. Taylor-Powell, E., Steele, E.: Collecting Evaluation Data: Direct Observations. University of Wisconsin, Madison (1996)

23. Mills, A., Durepos, G., Wiebe, E.: Encyclopedia of Case Study Research. Sage, California (2010)

24. Robinson, L.: The future of US special operations forces. Counc. Foreign Relat. 66, 1-39 (2013)

25. Chief of Staff of the Portuguese Army (CSPA): Âmbito de atuação, missões e tarefas das unidades de tropas especiais. Divisão de Planeamento de Forças, diretiva $n^{\circ} 90$ do Chefe de Estado-Maior do Exército Português (2007)

26. Knie, J.: Special Forces Skills: Are they Special Enough? U.S. Army War College, Carlisle Barracks PA. (2002)

27. Pordata: Students enrolled in higher education: total and by sex. Statistical database. https:// www.pordata.pt/en/Search/students\%20in\%20Portugal,\%20sex (2018)

28. Torrão, S.: Anjos na Guerra. Oficinas do Livro, 1-168 (2013)

29. Carreiras, H.: Women in the Portuguese armed forces: from visibility to eclipse. Curr. Sociol. 50(5), 687-714 (2002)

30. Grão, L.: Enfermeiras pára-quedistas 1961-2002. Prefácio (2006)

31. Haring, E.: What Women Bring to the Fight. Army War College Carlisle Barracks PA. (2013)

32. Cawkill, P., Rogers, A., Knight, S., Spear, L.: Women in Ground Close Combat Roles: The Experiences of Other Nations and a Review of the Academic Literature. Defense Science and Technology Labroratory, Porton Down (2009)

33. Doan, A., Portillo, S.: Not a woman, but a soldier: exploring identity through translocational positionality. Sex Roles 76(3-4), 236-249 (2017)

34. Ryan, M.: The Operators: Inside the World's Special Forces. Skyhorse Publishing Inc. (2008)

35. MNDRP, Ministry of National Defence Republic of Poland-Military service. http:// archiwalny.mon.gov.pl/en/strona/333/LG_260_261 (2018). Accessed 31 Oct 2018 